\title{
Crayfish Tonic Inhibition: Prolonged Modulation of Behavioral Excitability by Classical GABAergic Inhibition
}

\author{
Eric T. Vu and Franklin B. Krasne \\ Neuroscience Program, Department of Psychology, and the Brain Research Institute, University of California at Los \\ Angeles, Los Angeles, California 90024
}

\begin{abstract}
Previous studies have indirectly implicated the two neurotransmitters 5-HT and GABA in mediating tonic inhibition of the crayfish lateral giant (LG) escape reaction. In this study, pharmacological agents were selectively delivered to restricted portions of the abdominal CNS (where LG escape circuitry resides) to assess directly the role of these two transmitters in tonic inhibition. Both 5-HT and GABA depressed monosynaptic, electrical transmission to the LG neurons, the command neurons for LG escape, and application of either transmitter resulted in a depolarizing conductance increase in the LG neuron. The effects of 5-HT persisted in preparations in which chemical transmission was effectively abolished, implying that there are 5-HT receptors on the LG neuron itself, along with the known GABA receptors.
\end{abstract}

Restricted delivery of the GABA chloride channel blocker picrotoxin to only the abdominal CNS blocked the expression of tonic inhibition there (without interfering with the rostral generation of tonic inhibition). Therefore, if 5-HT mediated tonic inhibition, the effects of 5-HT on the abdomen should also be antagonized by picrotoxin. However, this was not the case, thus suggesting that 5-HT does not mediate tonic inhibition. The most likely neurotransmitter used for tonic inhibition is GABA acting via ligand-gated chloride channels. Thus, although this form of behavioral modulation can be tonically active for very long periods, it nevertheless appears to be mediated by a classical synaptic mechanism.

[Key words: GABA, crayfish, lateral giant, tonic inhibition, picrotoxin, 5-HT]

The crayfish lateral giant (LG) neurons, the command neurons for tail flip escape reactions, are subject to two functionally distinct types of inhibition. One, recurrent inhibition, is a phasic inhibitory process that prevents crayfish from starting a new escape response while a previously initiated one is being executed (Roberts, 1968). The other, tonic inhibition (TI), lowers the priority of escape behavior relative to other adaptive responses (Krasne and Wine, 1975; Krasne and Lee, 1988; Krasne et al., 1990; Vu and Krasne, 1992; Vu et al., 1993). TI can suppress escape over extended periods when crayfish are feeding

Received Sept. 18, 1992; revised Apr. 7, 1993; accepted Apr. 19, 1993.

We thank T. Teshiba for technical assistance and Dr. G. Laurent for discussion. This research was supported by a predoctoral NSF fellowship to E.T.V. and by NINDS Grant NS-08108 to F.B.K.

Correspondence should be addressed to Dr. Eric Vu, Division of Biology 21676, Caltech, Pasadena, CA 91125.

Copyright @ 1993 Society for Neuroscience $0270-6474 / 93 / 134394-09 \$ 05.00 / 0$ or when they are restrained firmly enough that a tail flip would not result in successful escape. The neural pathways producing these two forms of inhibition are distinct. Recurrent inhibition is mediated by synapses located on the main dendritic shaft of the LG neurons, proximal to the axon and its spike initiating zone (Roberts, 1968; E. T. Vu and F. B. Krasne, unpublished observations). TI is mediatcd by synapses locatcd relatively distally on the LG dendrites near where excitatory inputs innervate the neuron (Vu et al., 1993). The reasons for this anatomical segregation are discussed in the preceding article (Vu et al., 1993).

The present article is concerned with the neurotransmitters these pathways utilize. Recurrent inhibition, which requires brief action and precise timing for effective operation, is thought to be mediated by GABA presumably operating via ligand-gated chloride channels (Krasne and Roberts, 1967; Roberts, 1968). In contrast, the often prolonged periods of behavioral modulation exerted by TI seem well suited for mediation by a transmitter-activated $\mathrm{G}$-protein and/or second messenger cascade because changes in cellular excitability produced in this manner are usually more persistent and often thought of as modulatory in function (Kupfermann, 1979; Levitan, 1988). Consistent with this hypothesis is evidence for the involvement of the endogenous monoamine $5-\mathrm{HT}$ in the production of TI.

Specifically, 5-HT applied to the crayfish abdominal nervous system depresses synaptic transmission to the LG neurons without affecting transmission to the sensory interneurons of the escape circuit (Glanzman and Krasne, 1983), just as TI does. Furthermore, the neurotoxin 5,7-dihydroxytryptamine (5,7DHT), which lesions 5-HT-containing neurons, has been found to impair the production of TI (Glanzman and Krasne, 1986). That is, 5,7-DHT-treated crayfish appeared to have normal LG escape excitability when free but no longer suppressed escape when restrained. The specific physiological actions of 5-HT have also been implicated in other examples of behavioral modulation and plasticity (Kupfermann and Weiss, 1981; Kandel and Schwartz, 1982; Siegelbaum et al., 1982; Kravitz et al., 1983; Rosen et al., 1983, 1989; Lent and Dickinson, 1984; Goelet and Kandel, 1986; Kravitz, 1988; Lent et al., 1991).

However, a different line of investigation has suggested the involvement of GABA in TI. In a preliminary study (S. C. Lee and F. B. Krasne, unpublished observation), the GABA chloride channel blocker picrotoxin was found to abolish escape suppression when injected into the hemolymph of crayfish. Therefore, the purpose of this study was to clarify the roles of 5-HT and GABA in tonic inhibition, thus contributing to our understanding of the circumstances in which synaptic transmission 
involves indirect, second messenger-mediated actions or by direct actions on classical ligand-gated channels.

Preliminary reports of the work presented here have been published previously (Vu and Krasne, 1989; Krasne et al., 1990).

\section{Materials and Methods}

\section{Subjects}

Crayfish (Procambarus clarkii) of both sexes measuring $8-11 \mathrm{~cm}$ from rostrum to telson were obtained from various local suppliers and maintained individually.

\section{Physiological preparations}

Two types of preparation were used.

Isolated abdomens. This type of preparation was used to investigate the effects of 5-HT in the absence of TI, and to attempt to antagonize these effects. Animals were gradually cooled to about $5^{\circ} \mathrm{C}$ prior to starting dissection. The abdomen was separated from the thorax and pinned dorsal side up in a Sylgard-lined Plexiglas chamber. The terga and gut were removed, and the flexor musculature was separated at the midline to expose the ventral nerve cord (Krasne, 1969). Motor roots were cut in order to eliminate movements. If two microelectrodes were to be inserted, the sheath overlying the rostral, dorsal portion of either the third or fourth abdominal ganglion was removed. The LG was then impaled with one or two microelectrodes just rostral to the septal junction. A pair of platinum hook electrodes was used to stimulate primary afferent fibers in the ipsilateral second root of the ganglion under study. Pharmacological agents were delivered via a cannula inserted into the ventral artery that vascularizes the abdominal central nervous system (CNS), as describcd in Millcr ct al. (1992) and based on the methods of Mulloney et al. (1987). The entire preparation was immersed in chilled $\left(14-18^{\circ} \mathrm{C}\right)$ aerated Ringer's solution (van Harreveld, 1936).

Semi-intact preparations. This type of preparation was used to attempt to antagonize endogenously generated TI with pharmacological agents. Details of preparation of the animals and electrode placement are as described in the preceding article (Vu et al., 1993). Briefly, ventralside-up preparations were prepared for impalement of the LG neuron in either the fourth or sixth abdominal ganglion. However, the ventral artery overlying the abdominal CNS was not removed during surgery. Rather, it was held aside at the microelectrode impalement site with a minuten pin. The ventral artery was then cut caudal to the sixth abdominal ganglion, where it rapidly dips to join the dorsal artery, as well as rostrally at the level of the second abdominal ganglion, and a cannula was inserted into the sixth ganglion end of this isolated stretch of artery. Pharmacological agents could then be delivered exclusively to the abdominal CNS, or even exclusively to more caudal abdominal ganglia by making the rostral cut of the ventral artery at a more caudal segment of the nerve cord. Outflow from this cut end of the artery was rapidly diluted by the much larger volume of the circulating superfusion Ringer's bathing the animal. All preparations were prepared for reversible sucrose block of descending TI (see Vu et al., 1993). Stimulating and recording equipment were as described in $\mathrm{Vu}$ et al. (1993).

\section{Pharmacology}

Drug delivery to the cannula and preparation of drug solutions were as previously described (Glanzman and Krasne, 1983; Miller et al., 1992). Briefly, the cannula was attached to a four-way valve that received inputs from elevated reservoirs that were subjected to equal air pressure. Both the control and drug perfusion solutions were buffered to $\mathrm{pH} 7.3-7.4$ with 15 or $20 \mathrm{~mm}$ HEPES (isotonicity was maintained by reducing the $\mathrm{Na}^{+}$concentration). Baclofen, glycine, mianserin, picrotoxin, propranolol, serotonin creatinine sulfate, and spiperone were obtained from Sigma Chemical Co. (St. Louis, MO). 8-Hydroxy-2-(di- $n$-propylamino)tetralin (8-OH-DPAT) and ketanserin tartrate were obtained from $\mathrm{Re}$ search Biochemicals Inc. (Natick, MA).

To ensure reproducibility of the effects of $5-\mathrm{HT}$, frozen aliquots of crystalline 5-HT were made and fresh solutions were prepared prior to each experimental session.

\section{Results}

The starting points for this study were the findings that 5-HT mimics TI, while both 5,7-DHT and picrotoxin abolish $\mathrm{TI}$ in behavioral experiments. The first two findings suggest 5-HT mediation of TI, whereas the last suggests GABA mediation.

\section{Further characterization of the effects of 5-HT on $L G$}

Since the original report that 5-HT depresses root-evoked postsynaptic potentials (PSPs) in LG (Glanzman and Krasne, 1983), more has been learned about the physiological correlates of TI (Vu et al., 1993). We therefore performed a number of experiments designed to determine whether 5-HT mimics these newly discovered properties of TI.

Effects on components of the root-evoked PSP. TI depresses both the monosynaptic $(\alpha)$ and disynaptic $(\beta)$ components of the compound PSP recorded in LG following sensory root shocks, but depresses $\beta$ slightly more than $\alpha$ (Vu et al., 1993). This was also true for 5-HT applied to the nervous system of isolated tail preparations. Data from two different preparations are illustrated in Figure 1, $A$ and $B$ : at a concentration of $10^{-3}$ M, 5-HT reversibly depressed both the $\alpha$ - and $\beta$-components of the root PSP. This was seen in all 10 preparations examined (Fig. $1 C$ ).

That the $\alpha$-component was reduced by 5 -HT suggests that, as with $\mathrm{TI}$, direct excitatory transmission on $\mathrm{LG}$ was depressed. Additionally, as occurs during TI, $\beta$ was consistently reduced more than $\alpha$. The paired difference between percentage reductions of $\beta$ and $\alpha$ across the 10 animals in Figure $1 C$ was significant ( $11.47 \%$ mean difference, $\left.4.12 \mathrm{SD} ; t_{9}=8.81, p<0.001\right)$.

Dose-response measurements from this laboratory (D. L. Glanzman and F. B. Krasne, unpublished observations) showed that a 5-HT response is measurable at $10^{-6} \mathrm{M}$ and monotonically increases to a maximum at about $10^{-3} \mathrm{M}$. We used a high dose of 5-HT in this study to obtain a large response in order to detcet more clcarly the antagonism by other agents in experiments described below. However, in one other preparation (not shown), we found that the 5-HT $1 \mathrm{a}$-specific agonist 8-OH-DPAT (Peroutka, 1988) also reversibly depressed the root-evoked PSP by about $41 \%$ each of the four times it was applied to the preparation, but at the much lower concentration of $5 \times 10^{-5} \mathrm{M}$.

Effect on membrane potential. TI is associated with a depolarizing conductance increase in distal LG dendrites, resulting in a small depolarization at our microelectrode impalement site near the initial segment of the axon (Vu et al., 1993). Likewise, in four of five preparations where the $L G$ membrane potential was carefully monitored, 5-HT reversibly depolarized the LG membrane potential by an average of $1.73 \mathrm{mV}\left(1.10 \mathrm{SD} ; t_{4}=\right.$ $3.51, p<0.03$; Fig. $2 B$ ). Measurements from one preparation are shown in rigure $2 A$ (the mean control resting potential was arbitrarily set to zero).

Effects on LG input resistance. Because the $L G$ conductance increase activated by $\mathrm{TI}$ appears to be located in distal dendrites, only a small decrease in " $V_{\text {prox }}$," the voltage change produced at our impalement site (proximal to the axon) by current injection at that site, was detected in the presence of TI (see Fig. 6 of $\mathrm{Vu}$ et al., 1993). In contrast, current injected into the electrically coupled contralateral LG (see Fig. $3 A$, inset) must pass near relatively distal dendrites to reach our recording site and thus the resulting voltage change, " $V_{\text {contra }}$," is reduced much more than $V_{\text {prox }}$ by TI. Thus, we searched for evidence that 5-HT produces a conductance increase in LG by measuring $V_{\text {contra }}$. 5-HT reduced $V_{\text {contra }}$ in all four preparations examined by an average of $23 \%\left(6.2 \mathrm{SD} ; t_{3}=7.46, p<0.01\right.$; Fig. $\left.3 A\right)$. In two other preparations (not shown), we measured $V_{\text {prox }}$ during 5-HT application. No significant reduction of $V_{\text {prox }}$ was detected, consistent with the hypothesis that, as with TI, the LG conductance 

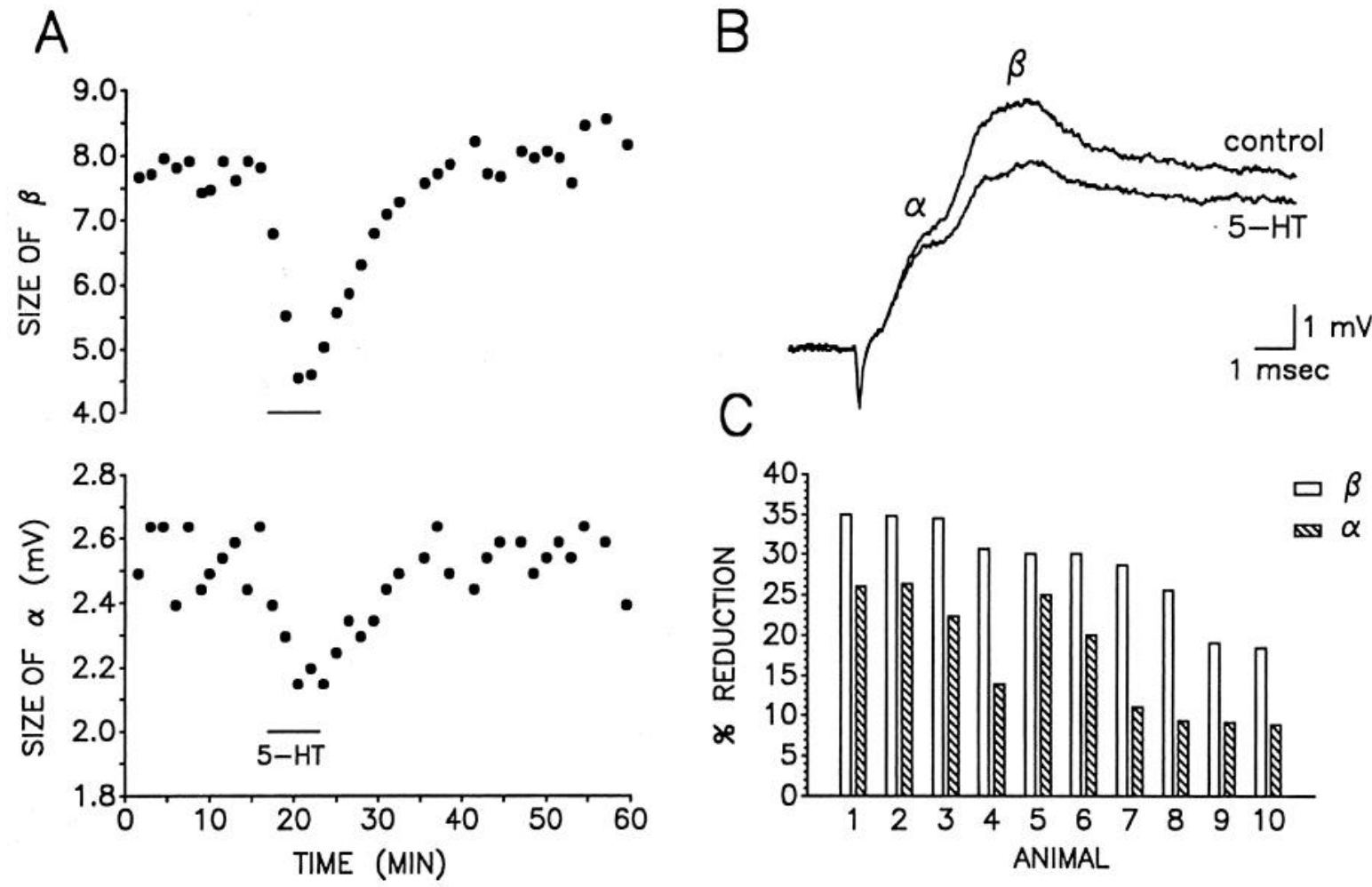

Figure 1. Effect of 5-HT on the root-evoked LG PSP. A, The $\alpha$ - (lower graph) and $\beta$ - (upper graph) components of a subthreshold root-evoked PSP in an isolated abdomen were repeatedly measured at once per $90 \mathrm{sec}$. 5- $H T$, short period during which 5-HT was delivered to preparation via the ventral artery. $B$, Sample traces from a different preparation than in $A$. A control PSP is superimposed with one evoked in the presence of $10^{-3} \mathrm{M}$ 5-HT (all 5-HT applications in following figures were at a concentration of $10^{-3} \mathrm{M}$ ). $C$, Percentage reduction of $\alpha$ and $\beta$ by 5-HT in 10 preparations.
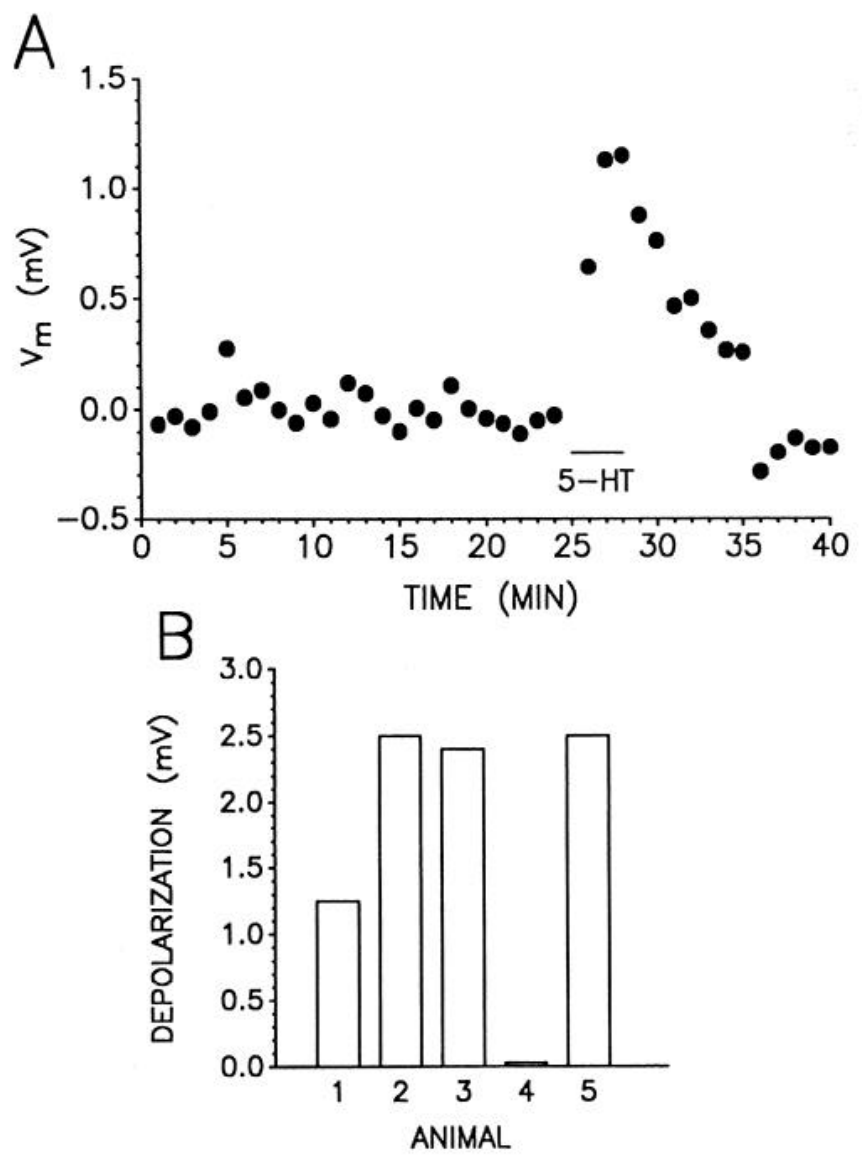

increase produced by 5 -HT is generated in relatively distal dendrites.

In order to establish that the effects of 5-HT on LG were not due to excitation of other neurons that then released transmitters on LG, we examined the conductance-increasing effects of 5-HT after $8 \mathrm{~mm}$ calcium in the perfusion Ringer's solution had been replaced with cobalt (Fig. $3 B$ ). This ionic substitution results in failure of all chemical synaptic transmission in this system (Miller et al., 1992). Consistent with this, the inset in Figure $3 B$ shows that the root PSP $\beta$-component but not the $\alpha$-component was abolished (compare Fig. 1B). The smaller trace shown was obtained during 5-HT application. Thus, reduction of both $V_{\text {contra }}$ and $\alpha$ by 5-HT persisted in the presence of cobalt, suggesting that there are 5-HT receptors on LG neurons themselves that could mediate TI.

In summary, these findings indicate that 5-HT, apparently via 5-HT receptors on LG distal dendrites, quite faithfully mimics the known properties of TI. However, a convincing case for mediation of TI by a particular transmitter requires antagonism of TI's effects by suitable pharmacological agents. The elimination of TI following systemic injections of 5,7-DHT or picrotoxin is not compelling because it leaves open the possibility that, rather than blocking the effects of the descending tonic

Figure 2. Effect of 5-HT on the LG membrane potential. $A$, The membrane potential was repeatedly measured and all values were normalized to the mean value before 5-HT application. A pulse of 5-HT was delivered at time indicated. $B$, The maximum depolarization caused by a pulse of 5-HT in five isolated abdomen preparations. 

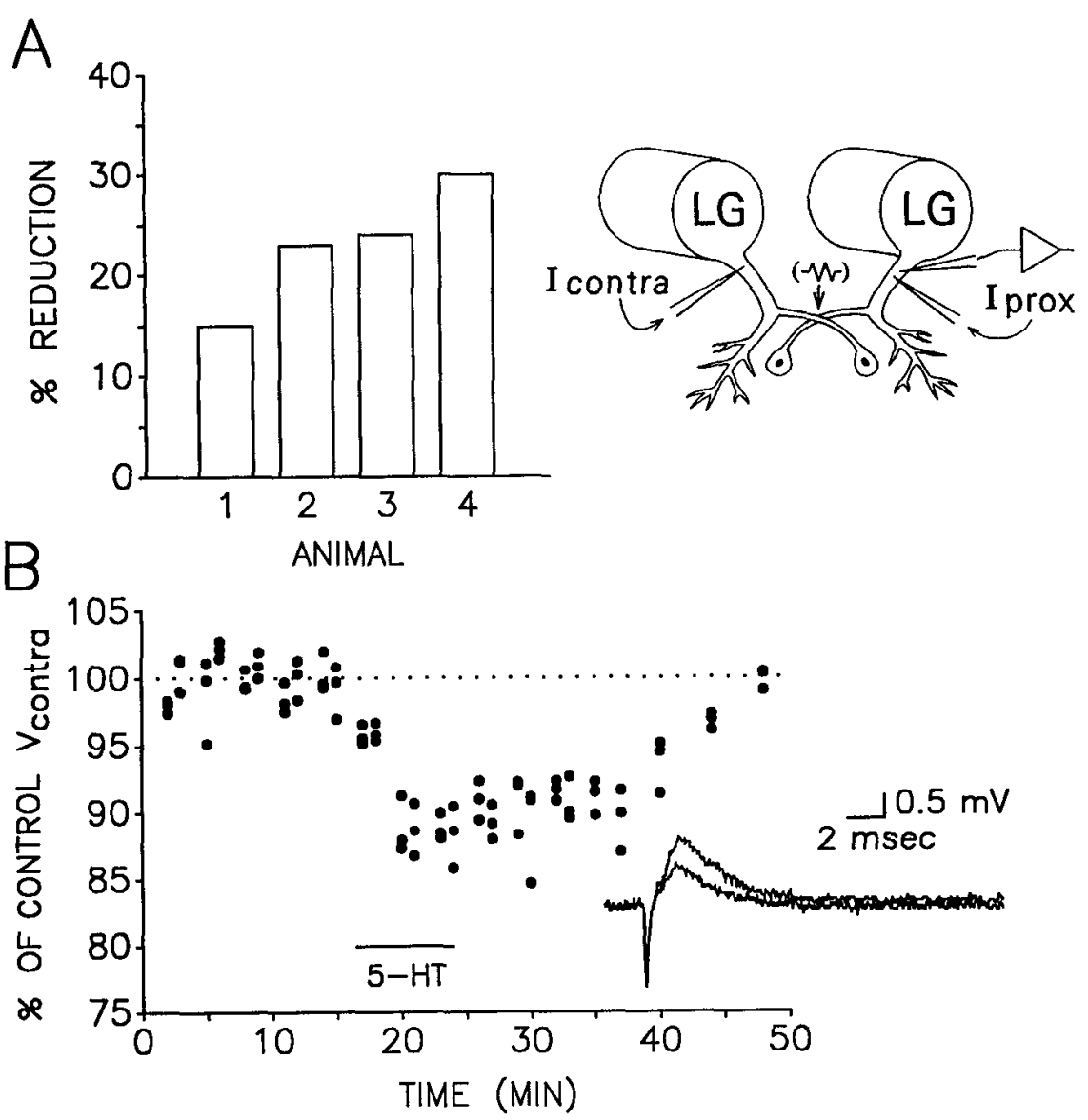

Figure 3. Effect of 5-HT on voltage produced by contralateral LG current injection $\left(V_{\text {contra }}\right)$. $A$, Peak percentage reduction of $V_{\text {contra }}$ by 5-HT application measured in four isolated abdomens. Inset shows arrangements of current injecting and recording electrodes; the bilateral LGs are electrically coupled by a commissural junction (resistor sym$b o l)$ located in dendrites distal from the axonal recording site. $B$, Data from animal 1 in $A$. The preparation was continuously perfused with Ringer's containing cobalt to block chemical synaptic transmission (see Results). Inset, because of cobalt application, the rootevoked PSP in this preparation was composed of only the monosynaptic, electrical $\alpha$-component. Two traces are supcrimposed; the smaller PSP was measured during 5-HT application. inhibitory pathway on the abdominal escape circuitry, these agents merely disrupted the operation of the rostral circuits from which the inhibition originates.

To distinguish between these possibilities, a means was developed to deliver drugs to only the abdominal portion of the CNS (see Materials and Methods). This was combined with a reversible sucrose block of descending fibers to assess whether TI was operating in each preparation (see Vu et al., 1993). It was thus possible to determine the effect of a pharmacological agent in both the presence and absence of TI.

\section{Antagonism of $T I$ by picrotoxin}

Using this abdominally confined delivery system we found that picrotoxin completely abolished TI. Data from four preparations are summarized in Figure 4. For each animal the peak amplitude of the root-evoked PSP (i.e., the $\beta$-component) was repeatedly measured, and all values were normalized to the mean value during an interval when effects of TI were shut off with sucrose block of descending fibers. Time-matched values were then pooled across animals.

Due to the necessary surgery, the recording sessions began after animals had been restrained for about $2 \mathrm{hr}$, by which time they were tonically inhibiting (see $\mathrm{Vu}$ et al., 1993). This was confirmed for each animal by showing that sucrose block of descending fibers reversibly disinhibited $\beta$ (Fig. $4 A$, left side; see also $\mathrm{Vu}$ et al., 1993). Picrotoxin $\left(7 \times 10^{-6} \mathrm{M}\right)$ was then continuously delivered (dashed line), resulting also in disinhibition of $\beta$. The mean normalized value of $\beta$ without sucrose block (i.e., in the presence of TI) and before picrotoxin application (82.3\%,
4.9 SD; Fig. 4B, 1st bar) was significantly different from that in picrotoxin $\left(98.6 \%, 3.1 \mathrm{SD}\right.$; Fig. $4 B, 3 \mathrm{rd}$ bar; $\left.t_{5}=5.48, p<0.01\right)$. Consistent with this, sucrose block no longer caused an increase in $\beta$ after picrotoxin block of TI (Fig. $4 B$, 3rd vs. 4th bars; $p>$ 0.05 ). We did not attempt picrotoxin washout, which usually takes a very long time (Krasne and Roberts, 1967; E. T. Vu, unpublished observation), because the gradual time course of deterioration of these semi-intact preparations, and therefore of rundown of TI, was on the same order as that of picrotoxin washout.

It was also possible to restrict delivery of pharmacological agents to only a subset of abdominal ganglia in the semi-intact preparation (see Materials and Methods). When thus restricted, picrotoxin blocked the effects of TI only at ganglia to which it was delivered and not at others (data not shown). Therefore, locally applied picrotoxin did not prevent the generation of TI but blocked its local effect.

\section{Further characterization of picrotoxin-sensitive receptors}

Because picrotoxin is a well-known blocker of the GABA-gated chloride channel, picrotoxin blockade of TI suggests GABA mediation. Therefore, we attempted to obtain additional evidence of GABA involvement in TI. Perfusion of isolated tail preparations with $\mathrm{GABA}\left(5 \times 10^{-4} \mathrm{M}\right)$ produced a depolarizing conductance increase in LG that was fully antagonized by picrotoxin at the same dose that abolished TI (Fig. 5). Note, however, that the GABA response was probably due at least in part to activation of the putative GABA receptors that mediate recurrent inhibition, which are also antagonized by picrotoxin. 

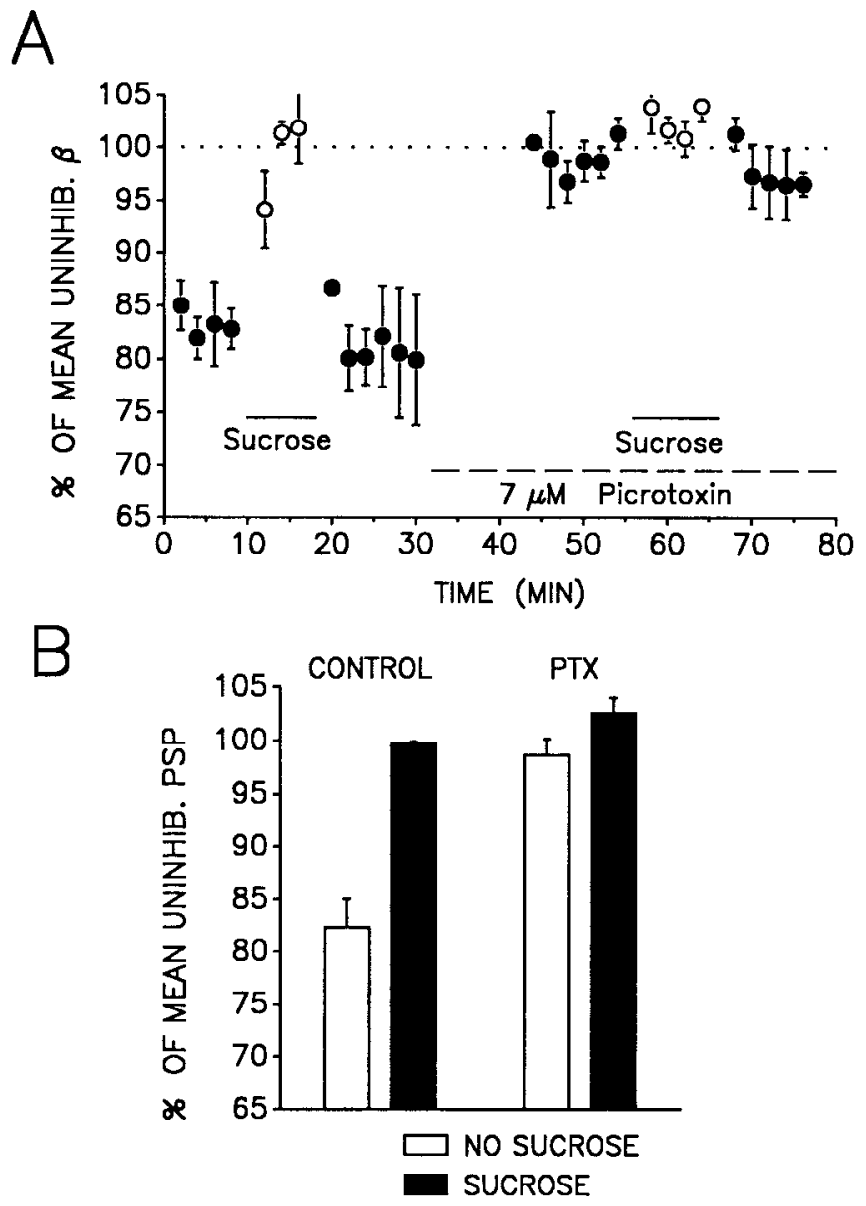

Figure 4. Effect of picrotoxin on semi-intact preparations. $A$, Normalized size of $\beta$ measured over the whole session (see Results). Timematched data from four preparations were pooled. Sucrose, periods during which sucrose connective block of descending pathways was applied. Dashed line indicates period during which picrotoxin was selectively delivered to the abdomen via the ventral artery. $B$, For each of the four animals in $A$, the mean normalized $\beta$-values across periods of sucrose block and unblock, before and during picrotoxin application, were determined. The averages of these across animals are shown.

Because the $\mathrm{GABA}_{\mathrm{B}}$-specific receptor agonist baclofen has been shown to mimic the effects of GABA and of presynaptic inhibition at a crayfish peripheral synapse (Blundon and Bittner, 1993), baclofen was also perfused here (at concentrations up to $5 \times 10^{-4} \mathbf{M} ; N=2$ ). However, it had no effect on either synaptic transmission to the LGs or the LG membrane potential, indicating that the GABA-evoked LG response was mediated by $\mathrm{GABA}_{\mathrm{A}}$ receptors. Antagonism of TI by $\mathrm{GABA}_{\mathrm{A}}$-specific antagonists needs to be demonstrated. Our attempts to antagonize TI with bicuculline (methiodide) have been unsuccessful to date, but we have not been able to antagonize recurrent inhibition with bicuculline either. Furthermore, bicuculline is not considered a reliable blocker of invertebrate $\mathrm{GABA}_{\mathrm{A}}$ receptors, which are known to be linked to chloride channels but which have a different pharmacological profile from that of vertebrate $G_{A B A}$ receptors (Simmonds, 1983).

A recent electron microscopic study of the inputs to the $\mathrm{LG}$ neurons (Lee and Krasne, 1993) revealed profiles adjacent to distal LG dendrites as well as others adjacent to the main proximal dendrite that made synapses on LG associated with elon- gated vesicles typical of GABAergic or glycinergic terminals (Korn et al., 1990; Kandel and Schwartz, 1991). We found that application of glycine (up to $5 \times 10^{-4} \mathbf{M} ; N=3$ ) had no effect on either synaptic transmission to the LGs or the LG membrane potential (data not shown), indicating that neither the proximal nor the distal inhibitory profiles represent glycinergic terminals on LG. Thus, because GABA could mimic the effects of TI on the IG neurons but neither baclofen nor glycine could and because the effects of GABA on LG are fully antagonized by the same dose of picrotoxin that abolished TI, we consider it likely that the blockade of TI by picrotoxin is due to antagonism of invertebrate type $\mathrm{GABA}_{\mathrm{A}}$ receptors on LG. However, the possibility remained that the picrotoxin-sensitive chloride channels of the LGs might be coupled to 5-HT receptors, as explored below.

\section{Attempts to antagonize the effects of 5-HT}

In an effort to find an antagonist that could be used to determine whether TI is serotonergic, we attempted to block the effects of 5-HT applied to isolated tail preparations by concurrently applying various specific antagonists of 5-HT receptors. However, we have not yet found a suitable blocker. The compounds tried include ketanserin, mianserin, propranolol, and spiperone. Figure 6 illustrates the general experimental paradigm. In each preparation, the peak amplitude of the root-evoked PSP (the $\beta$-component) was repeatedly measured once per minute. After control values were obtained, a pulse of $5 \times 10^{-4} \mathrm{M}$ to $10^{-3} \mathrm{M}$ 5 -HT was delivered through the ventral artery to show a normal response to $5-\mathrm{HT}$. A candidate antagonist was then continuously delivered (via the same artery). Additional 5-HT pulses were then occasionally delivered to assess possible antagonism. In Figure 6, the lack of antagonism by $5 \times 10^{-5} \mathrm{M}$ propranolol is illustrated. Higher doses and longer exposures were likewise ineffective $(N=4)$, although at $5 \times 10^{-4} \mathrm{M}$, propranolol severely and irreversibly depressed the root PSP.

Using abdominally confined delivery to semi-intact preparations we found that, as expected from their inability to antagonize 5-IIT effects, neither propranolol nor spiperone blocked TI (data not shown).

\section{Viable hypotheses}

The numerous ways in which 5-HT mimics TI support the hypothesis that 5-HT mediates TI. But the results of abdominally confined perfusion of picrotoxin show that TI involves a picrotoxin-sensitive step. Figure 7 portrays three different cellular pathways for TI that would be consistent with both sets of findings.

In hypothesis 1, GABA is the inhibitory transmitter but its release is either caused or presynaptically facilitated by serotonergic synapses. This possibility was of particular interest because the electron microscopic analysis of the LG dendrites by Lee and Krasne (1993) also revealed profiles containing large, dense-cored vesicles, typical of those seen in aminergic terminals, in close proximity to the morphologically defined inhibitory profiles mentioned above. Furthermore, this scenario exists in the neural circuit for the teleost Mauthner escape reflex. Mintz et al. (1989) showed that glycinergic inhibition of the Mauthner neuron is presynaptically facilitated by either $5-\mathrm{HT}$ or a $5-\mathrm{HT}$ uptake blocker and that 5-HT-containing terminals contact the inhibitors (see also Mintz and Korn, 1991).

In hypothesis 2, 5-HT is the inhibitory transmitter, and the LG receptors activated by it are coupled to a picrotoxin-sen- 


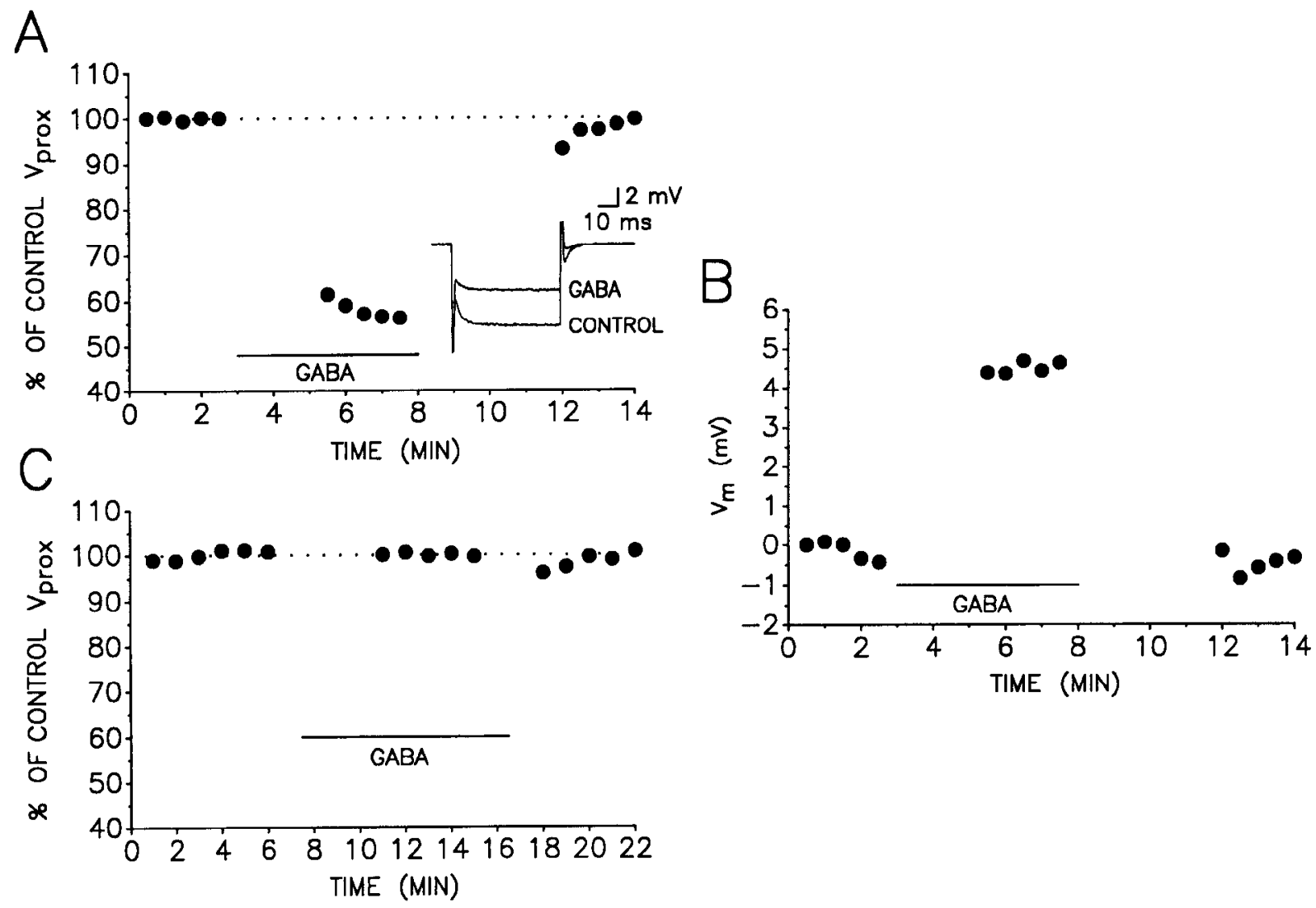

Figure 5. Effects of GABA on LG. $A$, Normalized size of $V_{\text {prox }}$, the voltage produced by current injected into the initial segment of the axon, over the session. $G A B A$, period during which $5 \times 10^{-4} \mathrm{M} \mathrm{GABA}$ was applied. Inset shows two superimposed sample traces, one before and one during GABA application. $B$, Normalized LG membrane potential from same preparation as in $A$. $C$, In a different preparation than in $A, 7 \times 10^{-6} \mathbf{M}$ picrotoxin was continuously perfused via the ventral artery. $V_{\text {prox }}$ was repeatedly measured and normalized to the mean value before GABA application. Application of $5 \times 10^{4} \mathrm{M}$ GABA no longer caused a reduction in $V_{\text {prox }}$. The membrane potential was likewise unaffected by GABA in the presence of picrotoxin.

sitive chloride channel either directly or indirectly via a G-protein (see Brown and Birnbaumer, 1988) or a second messenger cascade (see Nicoll, 1988).

In hypothesis 3, 5-HT is again the inhibitory transmitter, but neither the LG receptors activated by it nor the channels to which they are coupled are sensitive to picrotoxin. Rather, it is the excitation of the serotonergic inhibitors by descending TI fibers that is picrotoxin sensitive (see Fig. 7). This possibility is conceivable because picrotoxin at relatively high concentrations has been found to antagonize certain excitatory cholinergic and glutamatergic responses in crustacea (Marder and PaupardinTritsch, 1978, 1980; Miller et al., 1992; but see Discussion).

Of course, a fourth possibility is that 5-HT, though closely mimicking TI, does not actually mediate its abdominal effects. In that case TI would be most likely mediated by the GABA receptors on $L G$ described above.

\section{Lack of antagonism of 5-HT effects by picrotoxin}

If either hypothesis 1 or 2 of Figure 7 were correct, then picrotoxin should be able to antagonize the reduction of the rootevoked EPSP caused by 5-HT. However, this was not the case. Data from an isolated tail preparation are shown in Figure 8. A control pulse of 5-HT predictably reduced $\beta$ (compare Fig. 1). However, the 5-HT effect on $\beta$ was not at all reduced after more than $30 \mathrm{~min}$ of $10^{-5} \mathrm{M}$ picrotoxin perfusion, even when the picrotoxin concentration was higher than that used to abolish
TI (compare Fig. 4). At the same time, the medial giant-evoked, GABA-medialed, recurrent IPSP (Roberts, 1968) recorded in the same cell was reduced by about $75 \%$. Similar results were obtained in three other preparations. Thus, unlike TI, 5-HT

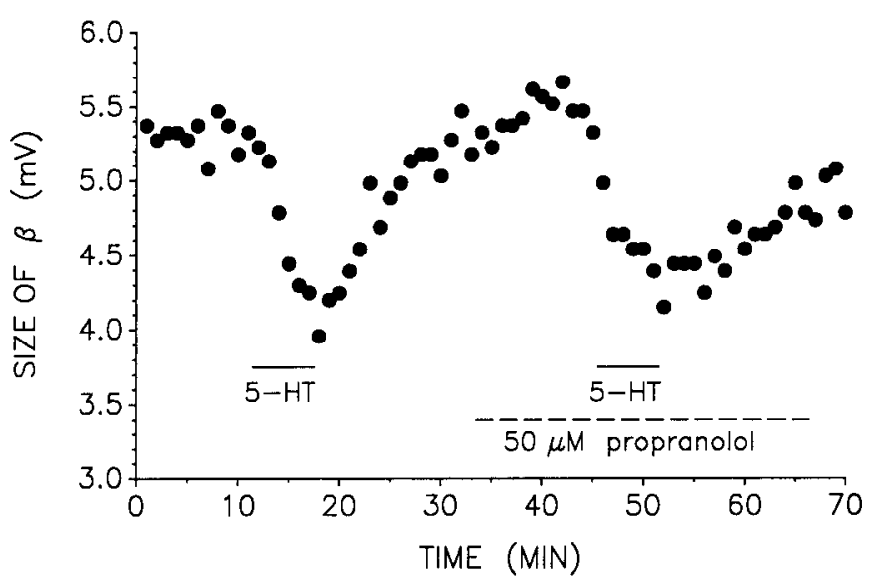

Figure 6. Lack of antagonism by propranolol of the 5-HT reduction of the root-evoked PSP $\beta$-component. Propranolol was delivered to an isolated tail preparation during the period indicated by the dashed line. Two pulses of 5-HT were delivered by the same means, one before and one about 12 min into application of propranolol. 

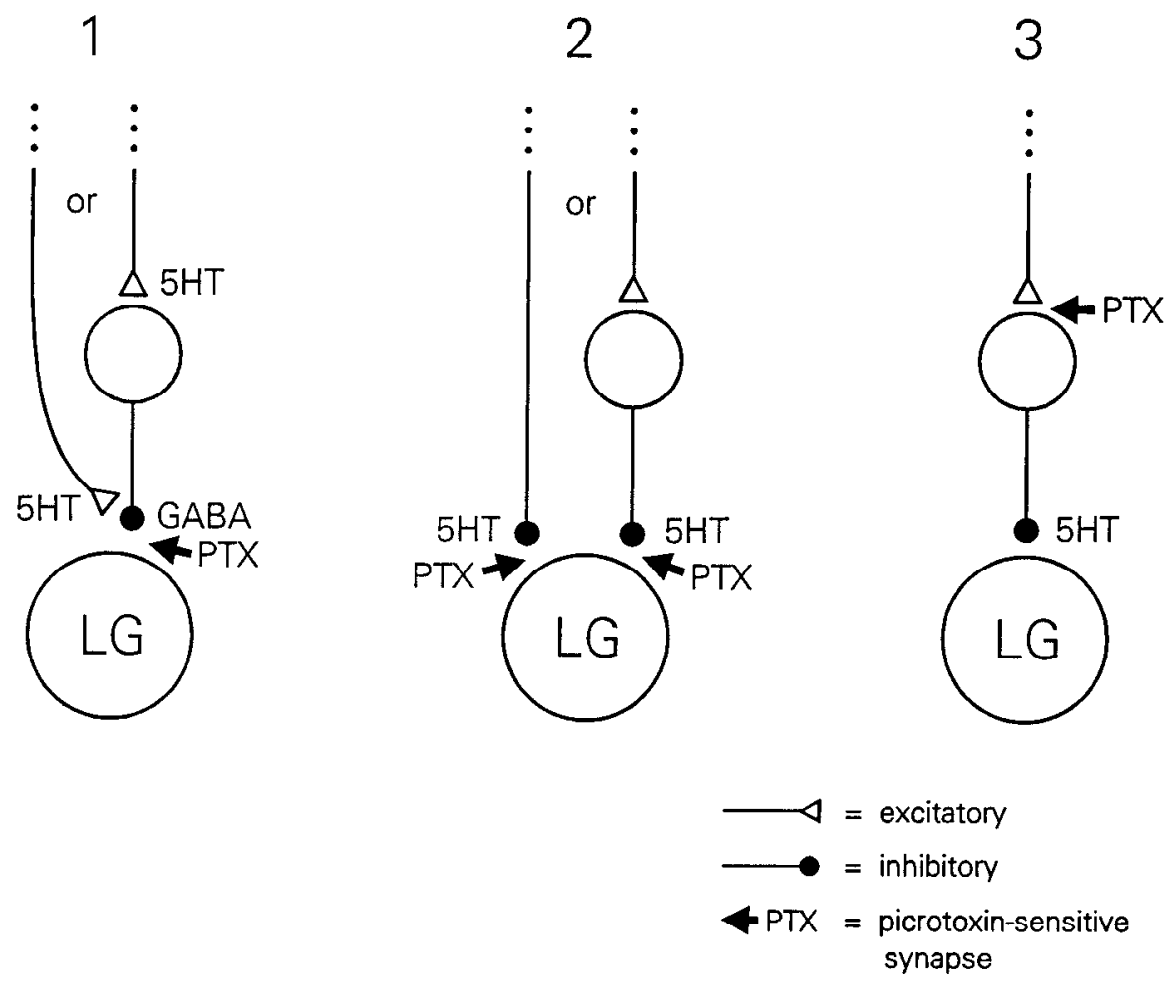

Figure 7. Three possible abdominal pathways to the lateral giant neuron $(L G)$ for TI. Large circles are schematic neurons or neuron classes. Triangles and small circles are axon terminals, with the postulated transmitter type they release indicated next to some terminals. In each alternative pathway, the synaptic locus that might be antagonized by picrotoxin is indicated by the arrow. See Results for details. synapse

does not seem to act on the escape circuit via a picrotoxinsensitive mechanism.

\section{Discussion}

Considerable circumstantial evidence suggests that the biogenic amine 5-HT mediates the form of modulation of escape known as tonic inhibition (TI). This article seems to add support to this hypothesis by showing that the inhibition of escape caused by 5 -HT has a number of newly discovered characteristics in common with TI. In particular, it provides evidence that the 5-HT receptors that modulate escape are on the LG command neurons, the locus of action of TI (Vu et al., 1993). Nevertheless, we believe that probably GABA, and not 5-HT, is the inhibitory transmitter used by the tonic inhibitory pathway.

We found that TI is abolished by local application of the GABA chloride channel blocker picrotoxin. In light of this, we evaluated three hypotheses (Fig. 7) that would reconcile this finding with 5-HT mediation of TI. The first and second hy-

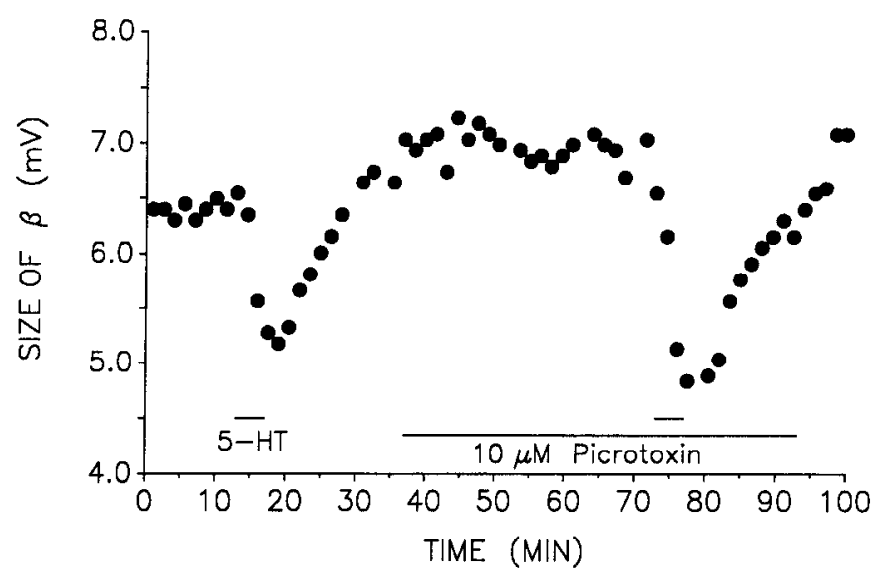

Figure 8. Lack of antagonism of 5-HT by picrotoxin. See Results. potheses, (1) that TI is mediated by GABAergic inhibition that is recruited by descending serotonergic fibers and (2) that TI is mediated by LG 5-HT receptors coupled to a picrotoxin-sensitive chloride channel, are ruled out by the contrasting findings that 5-HT-produced inhibition was unaffected whereas TI itself was abolished by picrotoxin.

The remaining hypothesis (3) is that picrotoxin antagonized the excitation of local serotonergic neurons by descending TI fibers. The basis for this hypothesis is the finding that a relatively high concentration of picrotoxin can antagonize certain excitatory cholinergic and glutamatergic responses in crustacea (Marder and Paupardin-Tritsch, 1978, 1980; Miller et al., 1992). I Iowever, whereas TI was completely abolished by $7 \times 10^{-6} \mathrm{M}$ picrotoxin, Marder and Paupardin-Tritsch (1980) reported that a picrotoxin dose of $5 \times 10^{-5} \mathrm{M}$ was needed to block only $50 \%$ of the ACh response in their study. Furthermore, cholinergic transmission between primary afferents and sensory interneurons in our preparations was unaffected by $7 \times 10^{-6} \mathrm{M}$ picrotoxin, as is evident in Figure 4, which shows that the size of $\beta$ of the root-evoked PSP was not significantly different before and after picrotoxin application, when TI was removed with sucrose block (Fig. $4 B$, 2nd vs. 4th bars; $p>0.05$ ).

Thus, we do not consider Hypothesis 3 plausible. We therefore believe that mediation of TI does not involve 5-HT. In light of this, we suggest that the abolition of TI by 5,7-DHT in behavioral experiments (Glanzman and Krasne, 1986) is due to disruption of the rostral centers that generate it. Indeed, trauma often interferes with TI (F. B. Krasne, unpublished observations), and 5,7-DHT-treated animals were often visibly sick and sometimes died.

The function of 5-HT receptors on IG whose activation mimics TI so convincingly remains a question. Indeed, the only difference we have detected between TI and 5-HT-produced inhibition is that the latter attenuated the root-evoked $\beta$-component slightly more relative to $\alpha$ than does TI (cf. Vu et al., 
1993). This difference might be due to the exact spatial distribution of receptors activated in the two cases or perhaps to a small effect of 5-HT at the first synapse of the escape circuit that was not detected in the study of Glanzman and Krasne (1983). The existence of a system of serotonergic cells in the abdominal nervous systems of crayfish and lobsters (Beltz and Kravitz, 1983, 1987; Glanzman and Krasne, 1986) and of aminergic-like terminals adjacent to LG dendrites (Lee and Krasne, 1993) suggests that there might be circumstances different from those that evoke TI in which a serotonergic form of distal inhibition of LG operates. Perhaps 5-HT is involved in some form of long-term regulation of $L G$ excitability (see Kravitz, 1988), or perhaps it is involved in some way with the tendency for crayfish to inhibit more rapidly and more strongly over repeated restraint sessions (E. T. Vu, K. Kawamura, and F. B. Krasne, unpublished observations). It seems likely to us that some function for these LG 5-HT receptors will ultimately be found.

The present data suggest that TI, like recurrent inhibition, is mediated by (GABA receptors linked to chloride channels on the LG neurons. This provides evidence that a clear instance of behavioral modulation that is often long lasting appcars to be mediated by inhibition that is of the classical, rapid, conductance-increasing type. Because of the apparent significance of biogenic amines in long-term behavioral states and their disorders in humans (Cooper et al., 1991) and because some of the specific cellular effects of amines in lower animals are plausibly viewed as modulatory in nature (e.g., Kupfermann and Weiss, 1981; Kandel and Schwartz, 1982; Lent and Dickinson, 1984; Kravitz, 1988), there is a tendency to expect modulation of behavioral responsiveness to be mediated by amines or by peptides, both of which commonly have indirect and prolonged cellular actions (McCormick, 1990; Kandel et al., 1991). The present data suggest that this is not necessarily the case.

\section{References}

Bcltz BS, Kravitz EA (1983) Mapping of serotonin-like immunoreactivity in the lobster nervous system. J Neurosci 3:585-602.

Beltz BS, Kravitz EA (1987) Physiological identification, morphological analysis, and development of identified serotonin-proctolin containing neurons in the lobster ventral nerve cord. J Neurosci 7:533546.

Blundon JA, Bittner GD (1992) Effects of ethanol and other drugs on excitatory and inhibitory neurotransmission in the crayfish. J Neurophysiol 67:576-587.

Brown AM, Birnbaumer L (1988) Direct $G$ protein gating of ion channels. Am J Physiol 254:401-410.

Cooper JR, Bloom FE, Roth RH (1991) The biochemical basis of neuropharmacology, 6th ed. New York: Oxford UP.

Glanzman DL, Krasne FB (1983) Serotonin and octopamine have opposite modulatory effects on the crayfish's latcral giant cscapc reaction. J Neurosci 3:2263-2269.

Glanzman DL, Krasne FB (1986) 5,7-Dihydroxytryptamine lesions of crayfish serotonin-containing neurons: effect on the lateral giant escape reaction. J Neurosci 6:1560-1569.

Goelet P, Kandel ER (1986) Tracking the flow of learned information from membrane receptors to genome. Trends Neurosci 9:492-498.

Kandel ER, Schwartz JH (1982) Molecular biology of learning: modulation of transmitter release. Science 218:433-443.

Kandel ER, Schwartz JH (1991) Directly gated transmission at central synapses. In: Principles of neural science, 3d ed (Kandel ER, Schwartz JH, Jessell TM, eds), pp 153-172. New York: Elsevier.

Kandel ER, Siegelbaum SA, Schwartz JH (1991) Synaptic transmission. In: Principles of neural science, 3d ed (Kandel ER, Schwartz JH, Jessell TM, eds), pp 123-134. New York: Elsevier.

Korn H, Faber DS, Triller A (1990) Convergence of morphological, physiological and immunocytochemical techniques for the study of single Mauthner cells: In: Handbook of chemical neuroanatomy, Vol 8, Analysis of neuronal microcircuits and synaptic interactions (Bjorklund A, Hokfelt T, Wouterlood FG, van den Pol AN, eds), pp 403480. New York: Elsevier.

Krasne FB (1969) Excitation and habituation of the crayfish escape reflex: the depolarizing response in lateral giant fibers of the isolated abdomen. J Exp Biol 50:29-46.

Krasne FB, Lee SC (1988) Response-dedicated trigger neurons as control points for behavioral actions: selective inhibition of lateral giant command neurons during feeding in crayfish. J Neurosci 8:37033712 .

Krasne FB, Roberts A (1967) Habituation of the crayfish escape response during release from inhibition induced by picrotoxin. Nature 215:769-770.

Krasne FB, Wine JJ (1975) Extrinsic modulation of crayfish escape behavior. J Exp Biol 63:433-450.

Krasne FB, Vu ET, Lee SC (1990) The excitability of the crayfish lateral giant escape reaction: inhibitory control of the lateral giant dendrites. In: Frontiers in crustacean neurobiology (Wiese K, Krenz W-D, Tautz J, Reichert H, Mulloney B, eds), pp 316-322. Berlin: Birkhauser.

Kravitz EA (1988) Hormonal control of behavior: amines and the biasing of behavioral output in lobsters. Science 241:1775-1781.

Kravitz EA, Beltz BS, Glusman S, Goy MF, Harris-Warrick RM, Johnston MF, Livingstone MS, Schwarz TL, Siwicki KK (1983) Neurohormones and lobsters: biochemistry to behavior. Trends Neurosci $6: 345-349$

Kupfermann I (1979) Modulatory actions of neurotransmitters. Annu Rev Neurosci 2:447-465.

Kupfermann I, Weiss KR (1981) The role of serotonin in arousal of feeding behavior of Aplysia. In: Serotonin neurotransmission and behavior (Jacobs BL, Gelperin A, eds), pp 255-287. Cambridge, MA MIT Press.

Lee SC, Krasne FB (1993) Ultrastructure of the circuit providing input to the crayfish lateral giant neurons. J Comp Neurol 327:271-288.

Lent CM, Dickinson MH (1984) Serotonin integrates the feeding behavior of the medicinal leech. J Comp Physiol [A] 154:457-471.

Lent CM, Zundel D, Freedman E, Groome JR (1991) Serotonin in the leech central nervous system: anatomical correlates and behavioral effects. J Comp Physiol [A] 168:191-200.

Levitan IB (1988) Modulation of ion channels in neurons and other cells. Annu Rev Neurosci 11:119-136.

Marder E, Paupardin-Tritsch D (1978) The pharmacolngical properties of some crustacean neuronal acetylcholine, gamma-aminobutyric acid, and L-glutamate responses. J Physiol (Lond) 280:213-236.

Marder E, Paupardin-Tritsch D (1980) Picrotoxin block of a depolarizing ACh response. Brain Res 181:223-227.

McCormick DA (1990) Membrane properties and neurotransmitter actions. In: The synaptic organization of the brain (Shepherd GM, ed), pp 32-66. New York: Oxford UP.

Miller MW, Vu ET, Krasne FB (1993) Cholinergic transmission at the first synapse of the circuit mediating the crayfish lateral giant escape reaction. J Neurophysiol 68:2174-2184.

Mintz I, Korn H (1991) Serotonergic facilitation of quantal release at central inhibitory synapses. J Neurosci 11:3359-3370.

Mintz I, Gotow T, Triller A, Korn H (1989) Effect of serotonergic afferents on quantal release at central inhibitory synapses. Science 245:190-192.

Mulloney B, Avecedo LD, Bradbury AG (1987) Modulation of the crayfish swimmerct rhythm by octopamine and the neuropeptide proctolin. J Neurophysiol 58:584-597.

Nicoll RA (1988) The coupling of neurotransmitter receptors to ion channels in the brain. Science 241:545-550.

Peroutka SJ (1988) 5-Hydroxytryptamine receptor subtypes. Annu Rev Neurosci 11:45-60.

Roberts, AM (1968) Recurrent inhibition in the giant-fibre system of the crayfish and its effect on the excitability of the escape response. J Exp Biol 48:545-567.

Rosen SC, Kupfermann I, Goldstein RS, Weiss KR (1983) Lesion of a serotonergic modulatory neuron in Aplysia produces a specific defect in feeding behavior. Brain Res 260:151-155.

Rosen SC, Weiss KR, Goldstein RS, Kupfermann I (1989) The role of a modulatory neuron in feeding and satiation in Aplysia: effects of lesioning of the serotonergic metacerebral cells. J Neurosci 9:15621578.

Siegelbaum SA, Camardo JS, Kandel ER (1982) Serotonin and cyclic 
AMP close single $\mathrm{K}^{+}$channels in Aplysia sensory neurones. Nature 299:413-417.

Simmonds MA (1983) Multiple GABA receptors and associated regulatory sites. Trends Neurosci 6:279-281.

Van Harreveld A (1936) A physiological solution for freshwater crustaceans. Proc Soc Exp Biol Med 34:428-432.
Vu ET, Krasne FB (1989) Postsynaptic inhibition of the lateral giant neuron during restraint-induced suppression of crayfish escape. Soc Neurosci Abstr 15:1141.

Vu ET, Lee SC, Krasne FB (1993) The mechanism of tonic inhibition of crayfish escape behavior: distal inhibition and its functional significance. J Neurosci 13:4379-4393. 